The University of San Francisco

USF Scholarship: a digital repository @ Gleeson Library |

Geschke Center

Kinesiology (Formerly Exercise and Sport Science)

College of Arts and Sciences

2015

\title{
Gender Difference in Lower Limb Muscle Activity During Landing and Rapid Change of Direction
}

Gerwyn Hughes

University of San Francisco, ghughes@usfca.edu

NDally

University of Hertfordshire

Follow this and additional works at: https://repository.usfca.edu/ess

Part of the Sports Sciences Commons, and the Sports Studies Commons

\section{Recommended Citation}

Hughes, Gerwyn and Dally, N, "Gender Difference in Lower Limb Muscle Activity During Landing and Rapid Change of Direction" (2015). Kinesiology (Formerly Exercise and Sport Science). 47.

https://repository.usfca.edu/ess/47

This Article is brought to you for free and open access by the College of Arts and Sciences at USF Scholarship: a digital repository @ Gleeson Library | Geschke Center. It has been accepted for inclusion in Kinesiology (Formerly Exercise and Sport Science) by an authorized administrator of USF Scholarship: a digital repository@ Gleeson Library | Geschke Center. For more information, please contact repository@usfca.edu. 


\section{Gender difference in lower limb muscle activity during landing and rapid change of direction.}

\section{Summary (English)}

Objectives: The purpose of the study was to examine gender differences in lower limb muscle activity during jump landing and rapid change of direction. Equipment and Methods: Surface electromyography (EMG) of the rectus femoris, biceps femoris and gluteus maximus were recorded for 10 male and 10 female basketball, volleyball or netball players performing five repetitions each of two tasks; 1) landing from a maximal height vertical jump and, 2) 45ำ rapid change of direction on their dominant leg. Independent sample t-tests were conducted to determine sex differences and paired samples t-tests were conducted to determine task differences in peak EMG muscle activity. Results: Rectus femoris muscle activity was significantly greater in females compared to males during jump landings and rapid change of direction. Biceps femoris muscle activity was significantly greater in males compared to females during jump landing. No significant gender differences in gluteus maximus muscle activity were found during jump landings or rapid change of direction. These findings suggest that significant differences in muscle activity of the quadriceps and hamstrings exist between males and females when performing jump landing and change of direction movements which may place females at greater risk of ACL injury compared to males, for example.

KEWORDS: muscle activity, anterior cruciate ligament, electromyography. 


\section{INTRODUCTION}

Between $70 \%$ and $90 \%$ of anterior cruciate ligament (ACL) injuries have been reported to occur in non-contact situations (no direct contact with the knee) [1]. Most non-contact $A C L$ injuries appear to occur in situations involving one or more of the following manoeuvres: at foot strike with knee close to full extension during rapid change of direction, landing and deceleration [1, 2]. The incidence of ACL injury is therefore relatively high in sports such as basketball (0.06 per 1000 person days) [3] and volleyball (0.45 per 1000 person days) [3] that are characterised by a high frequency of landing [4], deceleration [5] or rapid change of direction [6]. The incidence of non-contact ACL injury in females has been reported to be 6 to 8 times greater than in males competing in the same sports [7, 8]. Various risk factors have been reported to be associated with the apparent increased incidence of $A C L$ injuries in females These include intercondylar notch width [9], $Q$ angle [10], patella tendon tibia shaft angle [11], ACL cross sectional area [12], joint laxity [13], hormonal influences [14], muscle strength [15], muscle stiffness [16], muscle activity patterns [17] and biomechanics of landing [15, 18, 19, 20, 21]. However, the risk factors for which there appears to be strong empirical evidence are those factors related to structures providing dynamic stability (i.e. stability provided by the muscles that cross the tibiofemoral joint) to the knee joint. In particular, landing biomechanics, muscle activity pattern, muscle strength and muscle stiffness [2, 22].

When providing dynamic stability of the knee, co-contraction of the knee flexors and extensors should, ideally, result in a zero shear load on the proximal tibia and, therefore, minimal strain on the knee ligaments [23]. However, if the shear load exerted by the quadriceps is greater than the shear load exerted by the hamstrings, 
a resultant anteriorly directed shear force may be exerted on the proximal end of the tibia, which will potentially cause anterior tibial translation and therefore is likely to increase ACL strain [24, 25]. This is known as quadriceps dominance, defined as a preferential activation of the quadriceps compared to the hamstrings when providing dynamic stability of the knee joint [26], which a number of studies have found to be greater in females than males during activities associated with ACL injury [17, 27, $28,29,30,31]$. Previous research has examined muscle activity of the quadriceps and hamstrings muscles during cutting [27, 30, 31, 32], single limb landings [28, 33], double limb stop/drop jump landings [34, 35] and squats [17]. The results of these studies tend to show that females exhibit greater activation of the quadriceps muscles compare to males [27, 32, 28, 29, 30]. However, for the hamstrings, the findings are somewhat conflicting since some studies report no significant difference between males and females [29, 30, 33] whereas other studies report males to exhibit significantly greater muscle activity of the hamstrings compared to females $[34,36]$. The differences in the findings of these studies may be partly due to differences in the tasks examined, however there is little research investigating muscle activity of the same cohort of subjects during both landing and change of direction manoeuvres therefore it has not yet been established in the same group of subjects whether gender differences in lower limb muscle activity associated with ACL injury are consistent between both change of direction and landing tasks. Also, there is limited research examining muscle activity of the gluteus maximus during both landing and change of direction tasks which may also be associated with ACL injury since the gluteus maximus controls the alignment of the femur and the pelvis in all planes of motion during weight-bearing activities [37]. Recent research has begun to examine gender differences in gluteus maximus muscle activity during 
dynamic tasks and have found females to exhibit decreased gluteus maximus muscle activity compared to males [28], whereas other studies have shown no significant difference between males and females [32]. Therefore, further research is required to confirm these findings during different tasks and in different populations. Therefore the purpose of this study was to examine gender differences in muscle activity of the rectus femoris (RF), biceps femoris (BF) and gluteus maximus (GM) during jump landings and rapid change of direction.

\section{METHODS}

Following ethical approval, ten male (mean age 21.3 years \pm 0.9 , height $1.82 \mathrm{~m} \pm$ 0.09 and mass $79.5 \mathrm{~kg} \pm 10.2$ ) and ten female (mean age 20.3 years \pm 1.3 , height $1.68 \mathrm{~m} \pm 0.07$ and $64.6 \mathrm{~kg} \pm 10.8)$ subjects were recruited. Inclusion criteria for subjects included being aged between 18 and 25 years, no previous history of knee injuries and currently playing a court game sport (basketball, volleyball or netball) for

a team at least three times a week. Exclusion criteria included being pregnant, a history of knee injuries, presence of a long-term health conditions (medical or neurological), had not participated in any physical activity 24 hours prior to testing or reporting delayed onset muscle soreness of hamstrings and/or quadriceps immediately prior to testing.

Muscle activity was measured using electromyography (EMG) (Biometrics Ltd, Newport) with a sampling rate of $1000 \mathrm{~Hz}$. Integral dry reusable surface electrodes (SX230 Biometrics) with a fixed inter-electrode distance of $20 \mathrm{~mm}$ were attached using adhesive pads (T350). The skin of each electrode site was cleaned using 
alcohol wipes. Surface electrodes were placed on the dominant leg (determined as the leg they would push-off from during a jump) in accordance with Hermens at al. [38] recommendations for the RF (half way between the anterior inferior iliac spine and the proximal border of the patella), BF (half way in between the ischial tuberosity and lateral epicondyle of the tibia) and the GM (diagonally half way between the sacral vertebrae and the greater trochanter).

Prior to any testing, subjects carried out a five-minute warm up on the cycle ergometer at 70 RPM (revolutions per minute) followed by a standardised dynamic stretching protocol of the hamstring, quadriceps and gluteus maximus muscles. Following this, maximum voluntary isometric contractions (MVIC) of the RF and $\mathrm{BF}$ were recorded using the Biodex system II isokinetic dynamometer (Biodex Medical Systems Inc, New York) using knee flexion and extension against a fixed resistance. RF strength during knee extension was measured with the knee flexed between 60$80^{\circ}$ and biceps femoris strength was measured with the knee at $30^{\circ}$ of knee flexion, following the Hanson et al., [32] procedure. GM MVIC were measured whilst subjects lay on their side with a hook and loop strap $4 \mathrm{~cm}$ above their patella. Subjects abducted their hip against the strap with both knees flexed at approximately $30^{\circ}$, following the Leetun et al. [39] procedure. The reason the subjects were required to abduct rather than extend the hip was that the focus of our analysis was on the portion of GM muscle fibres that were involved in preventing excessive hip adduction during landing. Subjects performed two warm up trials at $50 \%$ and $75 \%$ of maximal effort followed by three five-second maximal trials, with two minutes rest between trials, as suggested by Hanson et al. [32]. Verbal encouragement was given to all 
subjects throughout the MVIC trials. The mean EMG activity during the middle three seconds of each trial was used for analysis.

Subjects were required to perform two tasks; a vertical jump landing and a rapid change of direction. Both tasks were found to be repeatable movements following pilot testing. During the jump landing task, subjects ran forwards three metres with maximal effort from a standing start and performed a maximal height vertical jump, taking off from and landing on their dominant leg. Subjects were not instructed to place their hands on their hips to replicate game specific movements. The rapid change of direction task consisted of the subjects running forwards three metres with maximal effort from a standing start and performing a side-cut manoeuvre which involved planting their dominant leg on the ground and then pushing off the ground to change direction by $45^{\circ}$ in the opposite direction of the leg they were pushing off. The order of the tasks was randomly assigned and all subjects performed three practise trials followed by five recorded trials for each task, with one minute rest between trials. EMG was recorded for the full duration of each task, however only the period between initial contact with the ground and maximum knee flexion of the contact phase (i.e. the landing period or the push off stride of the side cut) of each trial was used for subsequent analysis.

The EMG data were pre-amplified and set at a bandwidth of $20-450 \mathrm{~Hz}$, noise ratio of $<5 \mu \mathrm{V}$ and rejection ratio of $60 \mathrm{~Hz}(\mathrm{~dB}>96 \mathrm{~dB})$. EMG recordings were analysed using Biometrics' Datalink DLK900 (version 5.02) software. Raw EMG data for the MVIC and both tasks were processed at a five millisecond root mean square (RMS) 
moving window. The peak muscle activity during the contact phase of each trial (time between initial contact with the ground and maximum knee flexion) for each muscle was recorded. The data recorded during the dynamic tasks were then normalised to the EMG recorded during the MVIC tests in accordance with De Luca [40], therefore EMG data are reported as \%MVIC.

Statistical analysis was carried out using SPSS statistics 17.0. Normality tests were carried out using a Kolmogorov-Smirnov test and equal variance was assumed using a Levene's test for equality of variances. Independent sample t-tests were conducted to determine significant differences between males' and females' peak muscle activity of the RF, BF and GM in both tasks. Paired sample t-tests were conducted to establish significant differences in peak muscle activity of the RF, BF and GM between the jump landing and rapid change of direction tasks in males and females. Statistical significance was assumed at $p<0.05$.

\section{RESULTS}

All data were found to be normally distributed. Females displayed significantly greater peak RF muscle activity compared to males during both jump landing ( $p=$ $0.01)$ and rapid change of direction $(p=0.01)$ (Table 1 and Figure 1). Peak BF muscle activity was significantly greater in males compared to females during the jump landing $(p<0.001)$ (Table 1 and Figure 1$)$, however no significant difference was found during the rapid change of direction task $(p=0.17)$. No significant differences were found between males and females in peak GM muscle activity 
during jump landings ( $p=0.14)$ or rapid change of direction $(p=0.67)$ (Table 1 and Figure 1).

Table 1 about here.

Figure 1 about here.

For males, RF muscle activity was significantly greater during jump landings compared to the rapid change in direction $(p=0.01)$. However, BF $(p=0.09)$ and GM $(p=0.57)$ showed no significant difference in muscle activity between the two tasks for the males. Females showed no significant difference in RF $(p=0.95)$, BF ( $p$ $=0.65)$ and $\mathrm{GM}(p=0.36)$ muscle activity between jump landings and rapid change of direction.

\section{DISCUSSION}

Females exhibited significantly greater RF muscle activity than males during landing and rapid change of direction. This finding supports previous research which found significantly greater quadriceps muscle activity during landing and rapid change of direction [27, 28, 29, 30, 32]. Therefore whilst this might not be a novel finding in itself, the current study is the first to verify these findings for the same cohort of subjects during both single-limb landing and cutting tasks which exhibit high ecological validity. 
BF muscle activity was significantly greater in males compared to females during landing from a jump. However, no significant difference in BF muscle activity was found during rapid change of direction. Previous research examining gender differences in hamstring muscle activity during movements in which non-contact ACL injury is common (i.e. landing and cutting) has shown some conflicting findings whereby some studies report males to display greater hamstrings muscle activity than females [31, 36], whereas others report no significant difference between males and females [29, 30, 32, 33]. For example, Garrison et al. [33] found no significant gender difference in hamstring muscle activity during a $60 \mathrm{~cm}$ single leg drop landing, whereas Chappell et al. [34] found a significantly greater peak hamstrings muscle activity in males compared to females during landing from a vertical stop-jump task. The possible reasons for these conflicting findings may be due to differences in the level of ecological validity of the tasks employed or due to the normalisation methods used, whereby Garrison et al. [33] did not normalise EMG data.

No significant differences were found in GM muscle activity between males and females during jump landing or rapid change of direction. Similarly, Hanson et al. [32] found no significant gender difference in GM muscle activity during a side-step cutting task. Conversely, Zazulak et al. [28] found that muscle activity of the GM was significantly greater in males compared to females during single leg drop landings. The reasons for the difference between the findings of the current study and those of Zazulak et al. [28] may be due to differences in the tasks performed (drop landing v maximum height jump landing) and possible differences between MVIC tests and electrode placement, however Zazulak et al. [28] provide little information on these 
aspects of their study. It is also worth noting that the current study attempted to focus analysis on the portion of the GM muscle which is involved in abduction of the hip joint, which plays an important role in maintaining hip position limiting excessive adduction during landing/cutting tasks. Studies investigating gender differences in hip kinematics during landing have noted that females show increased hip flexion, abduction and external rotation compared to males [34], which may be due to reduced strength of the hip muscles, such as the GM. Hip abductors and external rotators, help maintain alignment of the lower extremity, especially resisting adduction loads at the knee [39]. Therefore, reduced strength of the GM in females may increase the strain on the support structures of the knee, such as the ACL. However, current research investigating the hip muscles as a risk factor for $A C L$ injury is unclear.

The results of this study show that generally, muscle activity was similar during landing from a jump and rapid change of direction. The activity of the RF was significantly greater during landing than rapid change of direction in males, but all other comparisons in muscle activity between tasks showed no significant differences. These results suggest that both landing and rapid change of direction produce similar lower limb muscle activity and therefore possess a similar risk of ACL injury. Although researchers such as Malinzak et al. [27] investigated gender differences in muscle activity during running, side-cutting and cross-cutting, no comparison between tasks was made. Therefore, little is known in terms of which tasks produce the greater muscle activities of the lower limb muscles in males and females and therefore may be more likely to cause ACL injury. These results 
provide some novel insight into task differences and the impact on ACL injury risk, however further investigation is needed.

\section{CONCLUSION}

Female court players displayed significantly greater RF muscle activity and significantly reduced BF muscle activity compared to males during jump landings and rapid change of direction. These findings suggest that muscle activity of the quadriceps and hamstrings may place females at greater risk of anterior tibial translation compared to males. No significant gender differences were found in GM muscle activity during jump landing or rapid change of direction, therefore the role of the GM in preventing anterior tibial translation risk remains inconclusive. Generally, muscle activity was similar during landing from a jump and rapid change of direction, suggesting that both manoeuvres possess a similar risk of anterior tibial translation in males and females. Preventative measures such as increasing hamstring strength in females may be necessary to decrease risk of anterior tibial translation.

\section{ACKNOWLEDGMENTS}

No author has received any financial benefit for the research in this study. We have no potential conflicts of interest relevant to the contents of this manuscript. 


\section{REFERENCES}

1 Griffin LY, Angel J, Albohm MJ, Arendt EA, Dick R W, Garrett WE, et al. Noncontact anterior cruciate ligament injuries: risk factors and prevention strategy. $\mathrm{J}$ Am Acad Orthop Surg 2000;8:141-150.

2 Hughes G, Watkins J. A risk factor model for anterior cruciate ligament injury. Sports Med 2006;36:411-418.

3 Beynnon BD, Vacek PM, Newell MK, Tourville TW, Smith HC, Shultz SJ, et al. The effects of level of competition, sport, and sex on the incidence of first-time noncontact anterior cruciate ligament injury. Am J Sports Med 2014;42:1806-1812.

4 Hopper D, Elliot B. Lower limb and back injury patterns of elite netball players. Sports Med 1993;16:148-162.

5 Miller MDM, Cooper DE, Warner JJP. Review of Sports Medicine and Arthroscopy. Philadelphia: WB Saunders; 1995.

6 Olsen OE, Mykelbust G, Engebretsen L, Bahr R. Injury mechanisms for anterior cruciate ligament injuries in team handball: A systematic video analysis. Am J Sports Med 2004;32:1002-1012.

7 Gwinn DE, Wilckens JH, McDevitt ER, Ross G, Kao TC. The relative incidence of anterior cruciate ligament injury in men and women at the United States naval academy. Am J Sports Med 2000;28:98-102.

8 Arendt EA, Dick R. Knee injury patterns among man and women in collegiate basketball and soccer. Am J Sports Med 1995;23:694-701. 
9 Ireland ML, Balantyne BT, Little K, McClay IS. A radiographic analysis of the relationship between the size and shape of the intercondylar notch and anterior cruciate ligament injury. Knee Surg Sports Traumatol Arthrosc 2001;9:200-205.

10 Shambaugh JP, Klein A, Herbert JH. Structural measures as predictors of injury in basketball players. Med Sci Sport and Exerc 1991;23:522-527.

11 Nunley RM, Wright D, Renner JB, Yu B, Garrett WE. Gender comparison of patella tendon tibial shaft angle with weight bearing. Res Sports Med 2003;11:173185.

12 Charlton WPH, St John TA, Ciccotti MG, Harrison N, Scheitzer M. Differences in femoral notch anatomy between men and women - A magnetic resonance imaging study. Am J Sports Med 2002;30:329-333.

13 Uhorchak JM, Scoville CR, Williams GN, Arciero RA, St Pierre P, Taylor DC. Risk factors associated with noncontact injury of the anterior cruciate ligament: A prospective four-year evaluation of 869 West Point cadets. Am J Sports Med 2003;31:831-842.

14 Wojtys EM, Huston LJ, Boynton MD, Spindler KP, Lindenfeld TN. The effect of menstrual cycle on anterior cruciate ligament injuries in women as determined by hormone levels. Am J Sports Med 2002;30:182-188.

15 Salci Y, Kentel BB, Heycan C, Akin S, Korkusus F. Comparison of landing manoeuvres between male and female college volleyball players. Clin Biomech 2004;19:622-628.

16 Wojtys EM, Huston LJ, Shock HJ, Boylan JP, Ashton-Miller JA. Gender differences in muscular protection of the knee in torsion in size-matched athletes. $\mathrm{J}$ Bone Joint Surg 2003;85A:782-789. 
17 Zeller LB, McCrory LJ, Kibler B, Uhl T. Differences in kinematics and electromyographic activity between men and women during the single-legged squat. Am J Sports Med 2003;31:449-456.

18 Chappell DJ, Yu B, Kirkendall DT, Garrett WE. A comparison of knee kinetics between male and female recreational athletes in stop-jump tasks. Am J Sports Med 2002;30:261-267.

19 Yu B, Lin CF, Garrett WE. Lower extremity biomechanics during the landing of a stop-jump task. Clin Biomech 2006;21:297-305.

20 Kernozek TW, Torry MR, Van Hoof H, Cowley H, Tanner S. Gender differences in frontal plane and sagittal plane biomechanics during drop landings. Med Sci Sport Exerc 2005;37:1003-1012.

21 Decker MJ, Torry MR, Wyland DJ, Sterett WI, Steadman JR. Gender differences in lower extremity kinematics, kinetics and energy absorption during landing. Clin Biomech 2003;18:662-669.

22 Hughes G. A review of recent perspectives on biomechanical risk factors associated with anterior cruciate ligament injury. Res Sports Med 2014;22:193-212.

23 Yeadon MR, King MA, Forrester SE, Caldwell GE, Pain MT. The need for muscle co-contraction prior to a landing. J Biomech 2010;43:364-369

24 Hewett TE, Ford KR, Hoogenboom BJ, Myer GD. Understanding and preventing ACL injuries: current biomechanical and epidemiologic considerations. $\mathrm{N}$ Am J Sports Phys Ther 2010;5:235-251

25 Pappas E, Zampeli F, Xergia S, Georgoulis A. Lessons learned from the past 20 years of $A C L$ related in-vivo biomechanics research of the knee joint. Knee Surg Sports Traumatol Arthrosc 2013;21:755-766. 
26 Ford KR, Myer GD, Hewett TE. Valgus knee motion during landing in high school female and male basketball players. Med Sci Sports Exerc 2003;35:1745-1750.

27 Malinzak RA, Colby SM, Kirkendall DT, Yu B, Garrett WE. A comparison of knee joint motion patterns between men and women in selected athletic tasks. Clin Biomech 2001;16:438-445.

28 Zazulak BT, Ponce PL, Straub SJ, Medvecky MJ, Avedisian L, Hewett TE. Gender comparison of hip muscle activity during single-leg landing. J Orthop Sports Phys Ther 2005;35:292-299.

29 Fagenbaum R, Darling GW. Jump landing strategies in male and female college athletes and the implications of such strategies for anterior cruciate ligament injury. Am J Sports Med 2003;31:233-240.

30 Sigward SM, Powers CM. The influence of gender on knee kinematics, kinetics and muscle activation patterns during side-step cutting. Clin Biomech 2006;21:41-48. 31 Landry SC, McKean KA, Hubley-Kozey CL, Stanish WD, Deluzio KJ. Gender differences exist in neuromuscular control patterns during the pre-contact and early stance phase of an unanticipated side-cut and cross-cut maneuver in 15-18 years old adolescent soccer players. J Electromyogr Kinesiol 2009;19:370-379.

32 Hanson AM, Padua DA, Blackburn JT, Prentice WE, Hirth CJ. Muscle activation during side-step cutting maneuvers in male and female soccer athletes. J Athl Train 2008;43:133-143.

33 Garrison CJ, Hart MJ, Palmieri MR, Kerrigan CD, Ingersoll DC. Lower extremity EMG in male and female soccer players during single-leg landings. J Sports Rehab $2005 ; 14: 48-57$ 
34 Chappell DJ, Creighton AR, Giuliani C, Yu B, Garrett EW. Kinematics and electromyography of landing preparation in vertical stop-jump. Am J Sports Med 2007;35:235-241.

35 Shultz JS, Nguyen DA, Leonard DM, Schmitz JR. Thigh strength and activation as predictors of knee biomechanics during a drop jump task. Med Sci Sports Exerc 2009;41:857-866.

36. Urabe Y, Kobayashi R, Sumida S, Tanaka K, Yoshida N, Nishiwaki GA, et al. Electromyographic analysis of the knee during jump landing in male and female athletes. Knee 2005;12:129-134.

37 Hollman HJ, Ginos EB, Kozuchowski J, Vaughn SA, Krause AD, Youdas WJ. Relationship between knee valgus, hip-muscle strength, and hip-muscle recruitment during a single-limb step down. J Sport Rehabil 2009;18:104-117.

38 Hermens HJ, Freriks B, Merletti R, Stegeman D, Blok J, Rau G, Disselhorst-Klug C, Hägg G. European recommendations for surface electromyography. Roessingh Research and Development: Enschede. 1999.

39 Leetun DT, Ireland ML, Willson JD, Ballantyne BT, Davis IM. Core stability measures as risk factors for lower extremity injury in athletes. Med Sci Sports Exerc 2004;36:926-934.

40 De Luca CJ. The use of surface electromyography in biomechanics. J Appl Biomech 1997;13:135-163. 


\section{Tables}

Table 1: Peak muscle activity of rectus femoris (RF), bicep femoris (BF) and gluteus maximus (GM) during jump landing and rapid change of direction task in males and females.

\begin{tabular}{|c|c|c|c|c|}
\hline \multirow[b]{2}{*}{ Muscle } & \multicolumn{2}{|c|}{$\begin{array}{c}\text { Peak muscle activity during jump } \\
\text { landing (\%MVIC) }\end{array}$} & \multicolumn{2}{|c|}{$\begin{array}{l}\text { Peak muscle activity during rapic } \\
\text { change of direction (\%MVIC) }\end{array}$} \\
\hline & Males & Females & Males & Females \\
\hline $\mathrm{RF}$ & $149.3 \pm 42.9^{* \dagger}$ & $209.2 \pm 53.0^{*}$ & $130.1 \pm 43.0^{\star \dagger}$ & $215.2 \pm 80.5^{*}$ \\
\hline $\mathrm{BF}$ & $234.9 \pm 85.9^{*}$ & $114.5 \pm 58.2^{*}$ & $225.7 \pm 81.9$ & $158.0 \pm 126.0$ \\
\hline GM & $179.3 \pm 51.7$ & $150.2 \pm 31.0$ & $195.2 \pm 95.7$ & $180.3 \pm 52.8$ \\
\hline
\end{tabular}




\section{Figure captions}

Figure 1: Peak muscle activity pattern in jump landing and rapid change of direction in rectus femoris, bicep femoris and gluteus maximus in males and females. Data represents the mean peak EMG activity and error bars represent the standard deviation. ${ }^{*}=$ significant difference $(p<0.05)$. 